successive $b b$ fringes corresponds to change in optical path of $\lambda$. Hence,

$$
\mu=\frac{D}{d}
$$

An average value of several determinations embracing four orders of interference gave $\mu=\mathbf{1 . 9 5}$ for uranium oxide produced by anodic oxidation.

This value is in good agreement with the value for the refractive index determined by the previous method. The accuracy of the determination was limited by irregularities in the metal surface and by the broad fringes obtained, and it was not possible to determine whether $\&$ varied within the thickness of the oxide wedge.

A determination of the refractive index of thermally prepared uranium oxide by Brewster angle measurements on the polished face of a sintered block gave a much higher value, namely, $\mu=2 \cdot 26$ for uranium oxide produced thermally.

Using the value $\mu=1.95$, the growth-rate of the oxide during anodizing in ammonia solution was found to be $28 \mathrm{~A}$./V.

Acknowledgments are made to the U.K. Atomic Energy Authority (Harwell) for kindly sponsoring this research.

Metallurgy Department,

A. E. Stebbens

L. L. Shreir

Battersea Colloge of Technology, London, S.W.11.

Flint, O., Polling, J. J., and Charlesby, A., Acta Met., 2, 696 (1954). "Tolansky, S., "Vultiple-beam Interferometry" (Clarendon Press, 1948),

\section{Frequency of Meteorite Falls throughout the Ages}

As recently as in 1956 the late Prof. F. A. Paneth an authority on meteorite investigations, published a paper under the above heading ${ }^{1}$, in which he wrote : "iron and stone meteorites did not fall before the late Quaternary".

Thanks to studies carried out here in Sweden on the 'cosmic spherules' discovered by J. Murray in $1876^{2}$, which are present in the long cores of sediment raised from great ocean depths by the Swedish Deep Sea Expedition in 1947-48 by means of the Kullenberg piston-core sampler ${ }^{3}$, we are now able to refute this hypothesis. We have been able to extract from the sediments cosmic spherules identical with those described by Murray but in much greater numbers, from tens to a couple of thousands per kilogram of red clay ${ }^{4,5}$. Also in the deepest sections of cores from the Pacific Ocean, dating back to the Tertiary Age, such spherules were found. It is to be hoped that by more extensive investigations of this kind a new chronology for deep-sea deposits may be evolved, going back much further in time than is possible by means of radioactive measurements.

This communication (detailed papers are being prepared) is chiefiy meant to be a plea for studying the cosmic spherules present in long cores of sediment which will be obtained by future deep-sea expeditions. In case the plans for drilling a hole through the deepocean sediments down to the underlying bedrock, repeatedly referred to in Nature $^{6}$, are realized, a study of the cosmic spherules present in the different layers penetrated will afford a unique record of the variations in meteor frequency since the oceans came into existence. This result alone will make it eminently worth while to realize the grandiose project, the total costs of which will amount only to a fraction of the costs of sending a manned rocket to the Moon.

Hans Petrersson

Oceanographical Institute, Gothenburg.

"Paneth, F. A., "Vistas in Astronomy" (1956).

2 Murray, J., Proc. Roy. Soc. Edin., 9, 258 (1876).

${ }^{3}$ Kullenberg, B., Rep. Swed. Deep-Sea Expedition, 4 (1), 37 (1955).

4 Pettersson, H., Festskrift T. E. Broström (Göteborg, 1955).

5 Pettersson, H., and Fredriksson, H., Pacific Seience, 12, 71 (1958). ${ }^{6}$ Gaskell, T. F., Nature, 179, 692 (1958).

\section{Chemical Composition of Tektites}

Is a recent communication, Brian Mason ${ }^{1}$ asks that I supply a list of chemical compositions of sedimentary rocks which parallel those of the tektites. I offer the following references for his samples of tektites labelled $A_{1}-G_{1}$. The pages in the following list refer to Pettijohn's book on sedimentary rocks ${ }^{2}$. $A_{1}, 298 ; B_{1}, 364 ; C_{1}, 319 ; D_{1}, 319 ; E_{1}, F_{1}$ and $G_{1}, 306$. Except for water content, fair agreements between analyses can be secured by selecting analyses from these tables. The low water content of tektites is a real puzzle. There are some small differences in analyses between those listed by Pettijohn and the tektites. It is very probable that some granites of the composition listed by Mason are fused sediments. What would be more interesting than an argument about average sedimentary rocks would be a comparison of the composition of particular groups of tektites and sedimentary or igneous rocks in the general area in which the tektites are found. If cometary collisions melted the local rock and scattered the fragments over great distances ${ }^{3}$, it should be possible to find the original material at an appropriate place. But this requires study by an expert in these matters and probably additional observational data, and these cannot be supplied by me.

University of California,

$$
\text { Harold C. URey }
$$

La Jolla, California. March 17.

${ }^{1}$ Mason, B., Nature, 183, 254 (1959).

2 Pettijohn, F. J., "Sedimentary Rocks", 2nd edit. (Haxper and Bros., New York, 1957).

${ }^{3}$ Urey, H. C., Nature, 179, 556 (1957).

\section{BIOCHEMISTRY}

\section{Are Nucleoside Triphosphates Precursors of Mammalian Ribonucleic Acid in vivo?}

WHEN albino rats are kept for 6-7 weeks on a protein-free diet they lose about half their body. weight ${ }^{1}$. At the same time, almost 50 per cent of the liver proteins and ribonucleic acid disappear : this can only be explained by a decrease in their biosynthesis.

We have studied the liver supernatant, because in this particular fraction loss of nucleoside di- and tri-phosphates during differential centrifugation can be prevented by the addition of ethylenediamine tetraacetate to the separation medium, whereas nucleoside polyphosphates are hydrolysed to monophosphates in the mitochondria and microsomes.

Protein deprivation results in the disappearance of 56 per cent of the proteins and 36 per cent of the ribonucleic acid in the supernatant, while there is an accumulation of adenosine triphosphate $(4 \cdot 7$ times the control), guanosine and uridine triphosphates. 